\title{
The Psychologist:
}

\section{The Identity of Psychology}

\author{
Miguel Ricou ${ }^{1,2,3}$, Sílvia A. Cordeiro ${ }^{1,2}$, Amanda R. Franco ${ }^{4}$, Cristina Costa-Lobo ${ }^{3}$ \\ ${ }^{1}$ Faculty of Medicine, Porto University, Porto, Portugal \\ ${ }^{2}$ CINTESIS - Center for Health Technology and Services Research, Porto, Portugal \\ ${ }^{3}$ INPP, Portucalense University, Porto, Portugal \\ ${ }^{4}$ CIDTFF, Aveiro University, Aveiro, Portugal
}

\section{Corresponding author:}

Sílvia Amado Cordeiro ${ }^{1,2}$ | silviamarina@outlook.com
Received:

26 October 2017

Accepted:

27 Maio 2018

\begin{abstract}
Background: Today, psychology benefits from widespread acknowledgement, being taken into account and used in a growing number of spheres of society. Nonetheless, not always does this profession follow such acknowledgment, which becomes a real employability problem for psychologists who are looking for a job in Portugal. Moreover, in an ever more specialized and flexible world in what concerns professional identities and careers, the development of psychology as a profession demands the establishment of guidelines and limits, besides an introspective attitude about the current psychological practice. Otherwise, psychology as a profession risks losing its identity, shrinking with the pressure that is imposed on it by its different specialties and areas of action.

Goals: We characterized the perceptions of Portuguese psychologists about the exclusive goal of psychological intervention, the tasks that are exclusively performed by psychologists and, also, the tasks that are performed by psychologists but which may also be performed by other professionals who are not psychologists. This analysis aimed to reveal if psychologists share a common and clear standing on this matter.

Methods: We used a three open-answer question questionnaire, which was specifically designed for this study. Data analysis was performed using thematic categorical content analysis.

Results: Our results stress that psychologists lack agreement concerning the three questions under study, which created a significant number of subcategories. Furthermore, we found answers that are clearly incorrect regarding these three issues, as well as a lack of response from a few participants.

Discussion: We discuss the potential implications of the results for psychologists' professional practice, as well as for the construction of a solid identity that may promote the general public's trust in psychologists. Also, we reflect on the need to define a single and exclusive goal for psychological intervention, one that is able to integrate the diversity of interventions in the field of psychology.
\end{abstract}

\section{Keywords:}

Psychological intervention; Professional identity; Survey; Content analysis 


\section{Introduction}

The present research proposal emerges from a process of questioning and reflecting about the knowledge regarding the role of psychological intervention (PI) in today's society. The main goal is to deepen and comprehend the phenomena associated to psychologists' professional identity. Indeed, we aim to reflect about the reasons that have led to the development of psychological science, as well as to the emergence of a larger set of related activities. According to this perspective, it becomes important to understand the role of psychologists and the role of PI. Any profession demands a certain level of educationtraining or expertise, grounded on a set of principles, beliefs, or opinions, in order to attain a specific goal (Ricou, 2014). Hence, it is important that the goal of PI is clear, to avoid confusion about its identity and characteristics.

According to the assumptions defended by social psychology, identity may be defined as a collection of personal characteristics, built from social relationships and from the different roles that an individual plays throughout her/his lifespan, and that set her/him apart from others. In this regard, Coutinho (1999) states that human beings build identity from singular characteristics and social relationships. Moreover, Ciampa (1986) claims that identity modes are determined by the historical and social context in which an individual is placed. According to Jacques (1996), the different working spaces are opportunities for an individual to acquire attributes that qualify her/his professional identity. Likewise, Schein (1996) claims that a career is based not solely on building a structured professional life, but also on the way an individual develops and perceives her/his professional life. Assuming that the development of identity is inserted in individuals' social and relational context, the development of professional identity may also suffer the impact of different factors associated to the environment. Indeed, if we consider the great and swift changes that have been witnessed throughout time in concern to the job market, with new jobs arising while others disappear, it is clear to see how such changes create impacts in the workplace, in terms of professional identity and labor relationships. The field of psychology also exhibits this, with a set of activities associated to psychology appearing, yet stemming from different training and philosophical fields, such as coaching, psychotherapy or a group of therapies known as alternative therapies, such as reiki, biofield therapy, shamanism, among others.

Today's society stems from a long historical process with change of paradigms throughout time originating changes in values, beliefs and ideas concerning reality, and resulting from the world's growing complexity. One example is the evolution of the role given to women in society. Traditionally seen as mere wives and mothers who were subordinated to men's decisions, today, the role of women entails potential equity, with women playing a role that is becoming more and more active in society (Ricou, 2014). Also in the field of education there are multiple changes taking place at many levels, which indeed occur concurrently. Nowadays, there is a stronger autonomy in decision making from youth, following the idea that each one must seek and create her/his own path.

Such changes have contributed to a stronger appreciation of people and their individuality. This way, we have moved from a society in which social roles were assigned at birth, to a society in which each one must develop her/his own individual role (Mendras, 1975). These changes produce new challenges and needs, since a person's developmental process is ever more complex, depending strongly on personal initiative and skills, and not mostly of inherited social status. If in the past there was a tendency towards social equalization, with people being divided into classes, nowadays the aim is to promote individual idiosyncrasy. Today, individual autonomy is based on a person's relational nature, which is developed by relating to others, according to one's history and characteristics. Human dignity has become the core value to activate each person's individual fulfilment, thus promoting a better society (Ricou, 2014). 
The development of psychology was born associated to this new individual and social demand. It is a profession that has arisen, in a considerable part, to answer these new challenges. If it may be defined as the scientific study of behavior and mental processes (Atkinson, Atkinson, Smith, Bem, \& Nolen-Hoeksema, 2002; Eysenk, 1998; Pinto, 2001), its development must be associated to the growing importance of those processes to each person's individual and social progression.

This reflection about identity led by psychologists is a necessary one, not only in Portugal, but also in Europe and at an international level. Seeing that professions have become flexible, there are multiple educationtraining opportunities, reason why the specific contents of a technical education-training are being diluted - perhaps with someone's best interests at heart - in a specific science. Drawing on the complexity, multidisciplinarity and flexibility of today's social and professional realities, it is important to analyze how identity is built in the context of psychologists' training and professional practice.

If $\mathrm{PI}$ should have universal guiding principles (Gauthier, 2005; Ricou, Sá, \& Nunes, 2017), it is essential to reflect about the nature of the differences. In each country, psychologists' initial and specialized training take on diverse characteristics; likewise, their social image and the interaction with other professionals also assume differentiated forms. Hence, it is important to understand how these more contextual dimensions, along psychologists' own characteristics, interfere with the professional image, status, and autonomy of psychologists. Considering the relevance of psychological science and the emergence of activities that derive from it, it is urgent to delimit the professional identity of psychology, as well as its field of action. From here emerges the question about what distinguishes PI from other proximal interventions, comprehensive or transdisciplinary, that today install themselves in contexts that have been traditionally associated with the practice of psychology (health, education, work, justice), or in emergent contexts (sports, social, communication). What are the performing procedures that are exclusive to psychologists, and what are the activities that they share with other professionals? For example, we can hardly speak of an exclusive activity of psychologists other than psychological assessment. This is a central dimension of PI (Gonçalves, Simões, \& Almeida, 2017), with the aim of psycho-diagnosis. Psychologists, through tests and other assessment tools to measure and observe behavior, arrive to diagnoses and guide interventions (APA, 2017a).

The answers to these questions cannot be searched exclusively in the field of psychology, among their representative entities and their professionals, nor be confined to a single country. Nevertheless, the beginning of the answer must be searched for and elaborated taking into consideration the professional perceptions of psychologists themselves. This is the goal of the present study.

According to the literature (e.g., Hilgard, 1987; Ribeiro, 1989; Teixeira, 2004; Trindade \& Teixeira, 2002), the goal of PI is to promote individual well-being, with a particular focus on the clinical dimension of this profession. Certainly that, as a profession, psychology is divided into many specialties (OPP, 2016; European Federation of Psychologists' Associations EFPA, 2017). Nonetheless, it was in clinical psychology that this activity obtained greater recognition, mostly during the World War II period, with its contribution being particularly focused on the mental disorders shown by war victims (Goodwin, 2015; Leal, Pimenta, \& Marques, 2012). One can say that World War II was an historical milestone for the development of psychology. The American Psychological Association (APA), which until then was exclusively dedicated to the search of science, from that moment on decided to expand its mission to the advancement of psychology as a profession and as a mean to promote human well-being (Hilgard, 1987). Such advancement was mostly due to the work of clinical psychologists, who before the World War II were limited to administering tests, since diagnosis and intervention were tasks performed in the area of psychiatry (Goodwin, 2015). After World War II, clinical psychologists were no longer confined to testing, and started to be recognized as experts in diagnosis and intervention. This 
helped them to stop being subordinated to psychiatrists and become equals (Goodwin, 2015). This was how psychologists, and clinical psychologists in particular, searched for their own professional identity.

It is not the purpose of this work to present an historical review of the evolution of clinical psychology, but rather to analyze the impact that this specialty brought to the development of psychology as a profession. According to the European Commission, the rise of clinical psychology may have been precipitated by a higher number of psychologists in the clinical and health specialties (European Commission - EC, 2016). The expressively higher number of clinical and health psychologists in Portugal (64\%), followed by educational psychologists $(17 \%)$, is a clear example of this (OPP, 2014).

For a professional activity to exist, there must be a clear purpose to be attained, as well as singular methods and practices to describe it. It has been difficult to achieve a consensus about the goal(s) of PI and what differentiates it from any other professional activity. A fine example of this relates to the difference between psychotherapy, with origins in psychiatry (Jung, 1981), and PI. In fact, the relationship between these two forms of intervention is not clear. For instance, while in some countries (e.g., Brazil, Germany, Luxembourg) psychotherapy is seen as the corollary of a clinical psychologist's training (e.g., Wegner, 2012; Conselho Federal de Psicologia - CFP, 2000; Société Luxembourgeoise de Psychologie - SLP, 2015), in other countries it arises as a professional activity dissolved in models and professionals with a very different training and identity (e.g., Portugal). The chances are that if psychologists have difficulties in establishing this difference, the general public shall definitely be unable to do so.

In an increasingly specialized and flexible world in what concerns professional identities and careers, if psychology does not strengthen its identity, it risks getting lost in that same specialization and flexibility. If its members do not identify first with psychology, only then looking for their specialization inside PI, they risk assuming other identities. It is not uncommon to meet a psychologist who identifies herself/himself as a "psychotherapist", "coach", or "human resources manager". Very often it all depends from the social statuses and perceptions that each one of these designations and specializations holds for the public opinion and for other professional groups.

In light of the framework above, we found it important to define the fundamental and exclusive goals of PI, and thus, to contribute decisively to the debate around the definition of an identity for PI. Our general aim is to discuss the importance of $\mathrm{Pl}$ according to its exclusive goals and procedures, and to make it very clear for professionals and, through them, for the general public. Moreover, it is also necessary to clarify what unites intervention variants in one same wider field called psychology. To do so, the present study was conducted in Portugal, with the explicit purpose of replicating it in as many countries as possible in the near future. Such a confrontation of information, as well as the collection of input from many different world views, can contribute for the development of psychology.

\section{Methods}

\section{Participants}

Considering the exploratory nature of this study, the snowball methodological technique for data collection was used. This sampling technique uses reference chains, in which one individual indicates another to participate in the sample, so it is considered a type of non-probabilistic sample (Goodman, 1961). The snowball sampling was originally used by researchers to identify people who had certain characteristics that were necessary for a particular study; in turn, these people who were identified by the researchers mediated the contact with other people with the same characteristics through their personal network, and so on. We used this technique to reach participants from the different regions of the country, once they assured the inclusion criteria in this study. The inclusion criterium was to be a Portuguese psychologist.

This study's sample is composed of 200 Portuguese psychologists, ranging in age from 24 to 68 years old $(M=39.21, S D=9.2)$. The majority of the sample was female (85.5\%). In regard to professional experience, 
the psychologists who participated in this study have been in practice from one to 40 years ( $M=13.29$, SD $=9.2$ ), with different specialties of psychology. The sample distributed by dominant area of professional practice corresponds to 86 psychologists in clinical and health psychology, 43 in educational psychology and 16 in work, social and organizational psychology. The remaining respondents are distributed by the several advanced specialties in psychology, as defined by OPP (psychology of justice, sports psychology, psychogerontology, community psychology).

\section{Instruments}

Participants responded to a questionnaire elaborated specifically for this study. Besides demographic questions regarding age, gender, time of service, and specialty area, the questionnaire that was used includes three open-answer questions. Items were elaborated from a revision of the literature related to the construct we aimed to assess. Both face and content validity were assured, obtained via inter-rater agreement (Ribeiro, 1999). All questions were discussed previously concerning their theoretical and practical adequacy by specialists who are knowledgeable in the different areas of psychology (clinical psychology, educational psychology and organizational psychology). The final version of the questionnaire was sent to a group of psychologists to be tested. A total of 12 questionnaires were analyzed to determine if the questions provided relevant answers for the purpose of this study, besides assuring clarity, appropriate vocabulary, and logic. Three questions emerged from the pretest and the inter-rate agreement: (1) "What is the exclusive goal of psychological intervention that makes it unique when compared to any other profession or form of intervention?" ; (2) "In your opinion, what functions are exclusively performed by psychologists?"; and (3) "In your opinion, what functions performed by psychologists may be performed by other professionals who are not psychologists?" The open-answer questions allowed us to collect information about the way psychologists perceive their professional identity, as well as PI itself.

\section{Procedures}

The present study took place in three phases. In phase one, a systematic review of the literature was performed, in order to analyze the state of the art concerning the identity of psychology, both in Portugal and internationally. The research was carried out in the electronic databases APA PsycNET, ISI Web of Science, PsyclNFO and Scopus. We also used the Google search engine. The keywords "identity", "psychology", "professional" and "perceptions" were used in English, French and Portuguese. The combination of words were: "psychology identity", "professional identity" and "psychologist's perceptions". Inclusion criteria were: publications in English, French or Portuguese, studies in the field of psychology and/or that consider professional identity, quantitative and qualitative original studies. Exclusion criteria included studies in other languages and studies that did not consider themes in the field of psychology professional identity. From previous research, it was possible to ascertain the lack of literature about this issue, particularly in Portugal. Given the absence of further development about psychologists' professional identity, as well as about $\mathrm{Pl}$, both study goals and methodology were defined. To attain our set goals, and considering the purpose of studying a topic that is still understudied, a qualitative methodology was followed (Hammel, Carpenter, \& Dyck, 2000). Moreover, considering that the focus of this study was the perceptions of psychologists about the topic, qualitative analysis was again identified as the best way to analyze such perceptions. Thematic categorical analysis was used.

In phase two, the open-answer questions were elaborated and then submitted to evaluation through a pretest, as mentioned earlier in the instruments' section. Once the questions were designed and tested, the three-question questionnaire was made available to participants by sharing a link through direct e-mail to a convenience sample of psychologists and through on-line platforms (e.g., Facebook and LinkedIn). The invitation of new referrals was done by participants themselves (e.g., Facebook, "friends"). The questionnaire was answered on-line through the Google forms platform. This procedure was selected to increase participation, since a national dissemination of the 
questionnaire was intended. It is noteworthy that this procedure fits in the type of (snowball) sampling elected for this research study. Data collection took place from February to May 2017.

In phase three, data analysis was undertaken using the NVivo software (version 12), followed by the interpretation of data.

Participants' confidentiality and privacy principles were assured by collecting anonymous data.

\section{Data analysis}

In order to achieve the goals that were set for this study, a qualitative methodology was used, since it enables the researcher to interpret and understand a phenomenon from participants' personal meanings (Chizzotti, 2003). Here, content analysis was selected as our methodological referential. Content analysis is a collection of techniques used to analyze discourse, in order to make the content of a message explicit, and also to systematize it (Bardin, 2009). To do so, the selected technique was categorical analysis, by placing our focus on the examination of underlying themes thematic analysis. The selection of a theme as a coding unit is often done to analyze open-answers, with the aim of studying opinions (Bardin, 2009), reason why it made sense in light of the purpose of this research study.

Data analysis followed three chronological phases, as defined by Bardin (2009): pre-analysis, examination of the material, and data processing and interpretation of results.
According to this approach, a skimming reading was performed to explore the collected answers, hence drawing a few first impressions and reflections from the data. After reading the material several times, emergent themes and categories were identified. In other words, from the analysis of each question, we identified the coding units grouped into thematic clusters. This originated a list of categories, making it possible to draw inferences. The option was to use semantics and lexicon as coding criterion. For instance, at a semantic level, all quotes with a meaning related to "well-being" were grouped in the category "wellbeing"; in turn, lexicon enabled us to code data according to its sense. The same respondent could have indicated more than one idea/unit. The designation of categories was guided by participants' answers, yet also in light of the literature. In the process of naming categories, we considered the presence (or absence) of themes, and also their frequency. The NVivo (version 12 for $\mathrm{Mac}$ ) software was used to organize and code data.

The coding that emerged from this study is presented in Table 1. In the column referring to categories, the three themes that were the focus of this study are presented. In each category, a set of subcategories emerged according to the content of answers, which were given a name in light of the coding units (text fragments), which in turn are integrated in the context unit.

The content analysis was performed and coded by two psychologists with experience in this field. If in disagreement, the coding process was discussed with a third researcher.

Table 1. Content analysis: grid of categories and subcategories

\begin{tabular}{l:l}
\hline Categories & Subcategories \\
\hline & Promotion of well-being \\
& Psychological assessment \\
Promotion of change & Self-knowledge \\
& Counseling \\
& Understanding the individual \\
Perceptions about the exclusive & Promotion of mental health \\
goal of PI & Interpersonal relationship \\
& Promotion of development \\
& Therapeutic act (any specific and poorly defined change processes) \\
& Psychotherapy \\
& Promotion of emotional balance \\
& None \\
& Does not know/does not answer \\
\hline
\end{tabular}


Table 1. Content analysis: grid of categories and subcategories (continued)

\begin{tabular}{|c|c|}
\hline Categories & Subcategories \\
\hline $\begin{array}{l}\text { Perceptions about the activities that } \\
\text { are exclusively performed by psy- } \\
\text { chologists }\end{array}$ & $\begin{array}{l}\text { Psychological assessment } \\
\text { Psychological intervention } \\
\text { Psychotherapy } \\
\text { Vocational guidance and career development } \\
\text { Specific techniques of intervention (hypnotherapy, cognitive stimulation, family mediation, therapeutic } \\
\quad \text { plans, techniques and methods of study, recruitment and selection in human resources management) } \\
\text { Counseling } \\
\text { Management of psychological assessment tools } \\
\text { Teaching and training } \\
\text { Coaching } \\
\text { Psychological act } \\
\text { Clinical dimension of the profession } \\
\text { Research } \\
\text { Prevention } \\
\text { None } \\
\text { Does not know/does not answer }\end{array}$ \\
\hline $\begin{array}{l}\text { Perceptions about the activities that } \\
\text { are performed by psychologists yet } \\
\text { may also be performed by other } \\
\text { professionals }\end{array}$ & $\begin{array}{l}\text { None } \\
\text { Psychotherapy } \\
\text { Human resources management } \\
\text { Training and teaching } \\
\text { Specific techniques of intervention (cognitive stimulation, mediation and conflict management, social rein- } \\
\quad \text { sertion) } \\
\text { Administration and grading of instruments of psychological evaluation } \\
\text { Prevention } \\
\text { Counseling } \\
\text { Coaching } \\
\text { Social and community intervention } \\
\text { Psycho-pedagogical support } \\
\text { Vocational guidance and career development } \\
\text { Psychological assessment } \\
\text { Research } \\
\text { Sociocultural animation } \\
\text { Personal development } \\
\text { Administrative services } \\
\text { Palliative care } \\
\text { Intervention in crisis } \\
\text { Psychological intervention } \\
\text { Assessment and intervention in forensic areas } \\
\text { Does not know/does not answer }\end{array}$ \\
\hline
\end{tabular}

\section{Results}

Results are presented according to the three categories defined during content analysis: perceptions about the exclusive goal of PI; perceptions about the activities that are exclusively performed by psychologists; and perceptions about the activities that are performed by psychologists yet may also be performed by other professionals.

\section{Perceptions about the exclusive goal of PI}

According to the answers given by psychologists who participated in this study, there is apparently no consensus when it comes to define the exclusive goal of PI. This can be observed from the number of subcategories that emerged in this theme, as presented in Table 2. The counseling (psychological support) subcategory encompasses the answers related to support relationship and problem-solving. 
Table 2. Goals of Pl: coding frequency according to subcategory

\begin{tabular}{|c|c|c|c|}
\hline Subcategories & Frequency & Context Unit (e.g.) & $\%$ of participants \\
\hline Promotion of well-being & 32 & "The client's well-being is the exclusive goal" & 16 \\
\hline Psychological assessment & 30 & "Psychological assessment" & 15 \\
\hline Promotion of change & 26 & $\begin{array}{l}\text { "The promotion of behavioral change and beliefs, which starts with build- } \\
\text { ing a process"; "Cognitive change"; "Behavior change" }\end{array}$ & 13 \\
\hline Self-knowledge & 21 & $\begin{array}{l}\text { "Most of all, a psychologist's intervention aims to promote self-knowledge } \\
\text { in an individual/group, in the sense of a better understanding, integration, } \\
\text { adaptation, empowerment, and/or recovery"; "Promote self-knowledge, } \\
\text { in order to manage personal challenges better" }\end{array}$ & 10.5 \\
\hline Counseling & 19 & $\begin{array}{l}\text { "The support relationship"; "A support focused on the promotion of skills } \\
\text { and problem-solving" }\end{array}$ & 9.5 \\
\hline Understanding the individual & 14 & $\begin{array}{l}\text { "Understanding and evaluation of the human mind"; "Understanding of } \\
\text { internal functioning mental connections" }\end{array}$ & 7.0 \\
\hline Promotion of mental health & 12 & $\begin{array}{l}\text { "The mental health of the human being as a whole"; "A protective factor } \\
\text { for an individual's psychological health" }\end{array}$ & 6.0 \\
\hline Interpersonal relationship & 12 & $\begin{array}{l}\text { "Unconditional acceptance of the client, without prejudice or discrimina- } \\
\text { tion, and creation of therapeutic alliance"; "The establishment of a } \\
\text { privileged relationship" }\end{array}$ & 6.0 \\
\hline Promotion of development & 10 & $\begin{array}{l}\text { "Promotion of human development"; "Internal development of the per- } \\
\text { son, with respect for her/his individuality" }\end{array}$ & 5.0 \\
\hline $\begin{array}{l}\text { Therapeutic act (any specific and } \\
\text { poorly defined change processes) }\end{array}$ & 5 & "Therapeutic act", "Psychological act" & 2.5 \\
\hline Psychotherapy & 4 & $\begin{array}{l}\text { "Psychotherapy, CCT are strategies of psychologists, who learn techniques } \\
\text { to deal with the disorders and associated pathologies" }\end{array}$ & 2.0 \\
\hline Promotion of emotional balance & 4 & "Contribute to a dignified, active, emotionally balanced existence" & 2.0 \\
\hline None & 4 & “None" & 2.0 \\
\hline Does not know/does not answer & 14 & "I don't know" & 7.0 \\
\hline
\end{tabular}

\section{Perceptions about the activities that are exclusively performed by psychologists}

Regarding the analysis of the activities that are exclusively performed by psychologists, participants' answers were predominantly inserted in the subcategory referring to psychological assessment. From a total of 200 psychologists who participated in this study, 140 claim psychological assessment as an exclusive function of psychologists. Besides psychological assessment, some participants mentioned other exclusive activities within the same unit context, and for this reason we had to code the content of each answer in more than one category. The answers referring to psychological assessment and intervention are an example. Here, a few answers (e.g., "psychological assessment and intervention") were coded as psychological assessment and as $\mathrm{PI}$, and the same happened for the other subcategories. According to the analysis 
of data, the following subcategories hold a high number of answers: PI, with 65 references; psychotherapy, with 52; vocational guidance and career development, referred 23 times.
As for the analysis of the remaining results, they may be observed in Table 3. We present the subcategories shown earlier, their frequenc, and the context unit in which they were placed.

Table 3. Exclusive activities of psychologists: coding frequency according to subcategory

\begin{tabular}{|c|c|c|c|}
\hline Subcategories & Frequency & Context Unit (e.g.) & $\%$ of participants \\
\hline Psychological assessment & 140 & "Psychological assessment" & $70.0 \%$ \\
\hline Psychological intervention & 65 & $\begin{array}{l}\text { "Psychological consultation and psychological intervention are psy- } \\
\text { chologist's exclusive competencies" }\end{array}$ & $32.5 \%$ \\
\hline Psychotherapy & 52 & "Psychotherapeutic treatment" & $26.0 \%$ \\
\hline $\begin{array}{l}\text { Vocational guidance and career } \\
\text { development }\end{array}$ & 23 & "Vocational and career orientation"; "Talent management and careers" & $11.5 \%$ \\
\hline Specific intervention techniques & 16 & $\begin{array}{l}\text { "Cognitive stimulation"; "Family mediation"; "Hypnotherapy"; "Re- } \\
\text { cruitment and selection" }\end{array}$ & $8.0 \%$ \\
\hline Counseling & 15 & "Counseling"; "Psychological support in several areas" & $7.5 \%$ \\
\hline $\begin{array}{l}\text { Management of psychological as- } \\
\text { sessment tools }\end{array}$ & 14 & $\begin{array}{l}\text { "Administration of personality tests and inventories"; "Administration } \\
\text { of scales and evaluation tools" }\end{array}$ & $7.0 \%$ \\
\hline Teaching and training & 14 & $\begin{array}{l}\text { "Teaching in the area of psychology"; "Training in the area of psychol- } \\
\text { ogy" }\end{array}$ & $7.0 \%$ \\
\hline Coaching & 8 & "Coaching may only be performed by psychologists" & $4.0 \%$ \\
\hline Psychological act & 6 & $\begin{array}{l}\text { "Everything that fits into the psychological act itself, already ap- } \\
\text { proved" }\end{array}$ & $3.0 \%$ \\
\hline $\begin{array}{l}\text { Clinical dimension of the profes- } \\
\text { sion }\end{array}$ & 4 & $\begin{array}{l}\text { "I think the clinical area should be exclusively exercised by psychologists } \\
\text { with clinical training" }\end{array}$ & $2.0 \%$ \\
\hline Research & 2 & "Research" & $1.0 \%$ \\
\hline Prevention & 2 & $\begin{array}{l}\text { "The development of prevention programs involving any psychological } \\
\text { dimensions" }\end{array}$ & $1.0 \%$ \\
\hline None & 7 & “None" & $3.5 \%$ \\
\hline Does not know/does not answer & 12 & "I don't know" & $6.0 \%$ \\
\hline
\end{tabular}

Perceptions about the activities that are performed by psychologists yet may also be performed by other professionals

Similar to previous themes, many subcategories emerged from the participants' answers regarding activities that are performed by psychologists yet may also be performed by other professionals. In this particular theme, the number of subcategories is higher than in the other two themes, since there was a larger diffusion of the content of answers. The most frequent answer given by the participants was "none" $(n=44)$. In Table 4, referring to the answers distributed by different subcategories, one can see that frequency does not highlight any answer in particular. The most frequently identified activities concern psychotherapy ( $\mathrm{n}$ =29), human resources management $(n=26)$, training and teaching $(n=20)$, and specific intervention techniques $(n=20)$. It is noteworthy that 22 answers fit in 
the subcategory "does not know or does not answer". In this subcategory, not knowing emerged from all the answers mentioning "I do not know"; as for not wishing to answer, it emerged when the content of the answer did not properly reply to the formulated question.

Table 4. Activities performed by other professionals besides psychologists: coding frequency according to subcategory.

\begin{tabular}{|c|c|c|c|}
\hline Subcategories & Frequency & Context Unit (e.g.) & $\begin{array}{c}\% \text { of } \\
\text { participants }\end{array}$ \\
\hline None & 44 & $\begin{array}{l}\text { "I consider that there is no activity that can be done by other profes- } \\
\text { sionals" }\end{array}$ & $22.0 \%$ \\
\hline Psychotherapy & 29 & "It is acceptable that psychiatrists perform psychotherapy" & $14.5 \%$ \\
\hline $\begin{array}{l}\text { Human resources manage- } \\
\text { ment }\end{array}$ & 26 & "Recruitment and selection"; "Human resources management" & $13.0 \%$ \\
\hline Training and teaching & 20 & "Training in areas such as coaching"; "Teaching" & $10.0 \%$ \\
\hline $\begin{array}{l}\text { Specific techniques of inter- } \\
\text { vention }\end{array}$ & 20 & $\begin{array}{l}\text { "Cognitive screening"; "Conflict mediation"; "Development of social } \\
\text { skills and study competences" }\end{array}$ & $10.0 \%$ \\
\hline $\begin{array}{l}\text { Administration and grading of } \\
\text { instruments of psychological } \\
\text { evaluation }\end{array}$ & 14 & $\begin{array}{l}\text { "Administration of tests"; "Use of certain evaluation batteries (e.g. } \\
\text { Griffiths)" }\end{array}$ & $7.0 \%$ \\
\hline Prevention & 14 & "Prevention of risk behavior, specifically in the occupational context" & $7.0 \%$ \\
\hline Counseling & 13 & $\begin{array}{l}\text { "Counseling by doctors, nutritionists and nurses", "Emotional sup- } \\
\text { port" }\end{array}$ & $6.5 \%$ \\
\hline Coaching & 12 & "Coaching activities" & $6.0 \%$ \\
\hline $\begin{array}{l}\text { Social and community inter- } \\
\text { vention }\end{array}$ & 12 & "Intervention in the social area"; "Community intervention" & $6.0 \%$ \\
\hline Psycho-pedagogical support & 11 & "Evaluation in the context of learning processes" & $5.5 \%$ \\
\hline $\begin{array}{l}\text { Vocational guidance and ca- } \\
\text { reer development }\end{array}$ & 9 & "In an area focused on vocational guidance" & $4.5 \%$ \\
\hline Psychological assessment & 6 & "Psychological assessment (also performed by psychiatrists)" & $3.0 \%$ \\
\hline Research & 6 & "Research on psychological and/or emotional issues" & $3.0 \%$ \\
\hline Sociocultural animation & 3 & "Sociocultural animation activities" & $1.5 \%$ \\
\hline Personal development & 3 & "Personal development programs" & $1.5 \%$ \\
\hline Administrative services & 3 & "Administrative work"; "Scheduling queries" & $1.5 \%$ \\
\hline Palliative care & 2 & "Palliative care" & $1.0 \%$ \\
\hline Intervention in crisis & 2 & "Support in crisis situations" & $1.0 \%$ \\
\hline Psychological intervention & 2 & "Psychological intervention" & $1.0 \%$ \\
\hline $\begin{array}{l}\text { Assessment and intervention } \\
\text { in forensic areas }\end{array}$ & 1 & $\begin{array}{l}\text { "Intervention with aggressors or drug addicts carried out by criminol- } \\
\text { ogists and staff with academic training in forensic areas" }\end{array}$ & $0.5 \%$ \\
\hline $\begin{array}{l}\text { Does not know/does not an- } \\
\text { swer }\end{array}$ & 22 & $\begin{array}{l}\text { "I do not know"; "Other mental health technicians may intervene in } \\
\text { certain problems that are complementary to the psychologist" }\end{array}$ & $11.0 \%$ \\
\hline
\end{tabular}

\section{Discussion}

Starting with the first goal of our study, pertaining the definition of the specific goal(s) of $\mathrm{Pl}$, our results seem to show that there is no consensus among psychologists in concern to the exclusive goal of PI. Such a finding is congruent with the motivations that originated this study, which concern the difficulty in finding a common underlying perception about the goals of PI. In fact, the identification of multiple subcategories could suggest that Portuguese psychologists may hold different concepts about the goals of psychology.

The most frequent answer associates the exclusive goal of $\mathrm{PI}$ to the promotion of well-being. Indeed, some authors (e.g., Hilgard, 1987; Ribeiro, 1989; Teixeira, 2004; Trindade \& Teixeira, 2002) stress that this is exactly the goal of PI. Nonetheless, this goal can 
hardly help to create a clear distinction between $\mathrm{PI}$ and other professions in the health area. In other words, even if the promotion of well-being is indeed a goal of $\mathrm{PI}$, it is also a goal of other professions related to health care. Psychology was originally developed in the mental health field (e.g., Goodwin, 2015; Leal, Pimenta, \& Marques, 2012). Perhaps for that reason, about $65 \%$ of psychologists in Portugal have conducted their training in the clinical and health areas (OPP, 2014). Such a high percentage of clinical psychologists in our sample may help to explain why our results stress well-being as a goal of $\mathrm{PI}$, since clinical psychologists may feel very strongly about this role. Even so, it is hard to believe that promoting well-being could be considered a specific and exclusive goal of PI.

The second most cited goal by participants was psychological assessment. This answer is inevitably surprising. Psychological assessment is indeed a core dimension of PI (Gonçalves, Simões, \& Almeida, 2017), and yet, it aims a psychological diagnosis. In other words, it is through tests and other assessment tools that psychologists can measure and observe behavior, which enables them to elaborate a diagnosis and guide intervention (APA, 2017a). For that reason, it has an essentially technical and instrumental dimension. By tradition, psychology has faced many difficulties in establishing itself as a science. So, to assume that psychological assessment is the exclusive goal of PI may represent an attempt to validate its practice from the use of techniques, whether because of lack of knowledge or because of not being sure of which are its goals. Likewise, in a society where technology is ever more important, to legitimize a form of intervention solely on the grounds of an interpersonal relationship could create conceptual skepticism.

Counseling is also identified as an exclusive goal of PI. Even the notion of counseling has a complex definition in Portugal, being a term that is not often used, even if it is rather common in other countries (e.g., USA). According to the APA (2017b), counseling is a recognized specialty of psychology, one that gives particular attention to the emotional, social, academic, vocational and career, health, developmental, and organizational concerns throughout an individual's life path. The professionals who work in this area are called counseling psychologists by the APA. However, counseling exists as an autonomous profession in a few countries, which leads to further confusion in concern to what is indeed $\mathrm{PI}$ or counseling. Whether we see it as a psychological specialty or as an autonomous activity that is performed also by "non-psychologists", the term tells us nothing about the identity of psychology. On the contrary, it may even contribute to ignite the confusion surrounding these two activities, which should have more in common than something setting them apart. In light of the above, it does not seem a wise choice to presume that counseling is an exclusive goal of PI. In light of our results, we consider that it is necessary to clarify what are the differences between psychological counseling and the kind of counseling that is performed by individuals who lack training in psychology.

To promote change is one of the most cited goals. Once again, this goal seems to focus PI on the clinical and health dimensions, that is, to a change from a state that creates a disruption of functionality. Clearly, that change does not entail starting from a deficiency. However, it may be harder to sustain change as a goal of $\mathrm{PI}$ in the field of the work performed by psychologists in companies, in recruitment, or even in schools. The answers related to the clinical area are very frequent: to promote well-being, to promote change, to promote mental health, therapeutic practice, psychotherapy, and to promote emotional balance. These are the answers of 83 participants, who seem to associate the exclusive goal of PI to the practice of psychology in the clinical and health fields, which represents about $50 \%$ of the answers. This leaves us without an identity that would include all areas of psychology under the same umbrella.

Self-knowledge is stressed as the exclusive goal of PI by $10.5 \%$ of participants. Society supports and promotes the expression of individual differences, thus making the individual's development process more important and complex. Psychology emerges in this context as a professional activity that aims to assist and foster individual development in people's different life contexts (Ricou, 2014). In line with this 
perspective, the increased importance of individual's self-knowledge for a fitter adaptation becomes clear, as well as the need to look at psychology as a form of supporting individuals to recognize such characteristics. This aspect does not seem to be the one that is most frequently associated to the goals of psychology in the literature (e.g., Atkinson et al., 2002; Eysenk, 1998), and yet, we believe that it may deserve a deeper reflection.

It is striking that $9 \%$ of psychologists assume to ignore the goal of $\mathrm{Pl}$, or even state that there is none, hence somehow underestimating the existence of their own profession. This number, associated to the other participants (42\%) to whom the focus of $\mathrm{PI}$ is on technique (psychological assessment, counseling, interpersonal relationship, an understanding of the individual, therapeutic practice, psychotherapy) makes up more than $50 \%$ of the answers. This cannot go unnoticed and requires reflection.

We can say that psychological assessment is one of the most important tasks exclusively performed by psychologists (Gonçalves, Simões, \& Almeida, 2017; Ricou, 2014). In light of these results, $70 \%$ of psychologists identify psychological assessment as an exclusive task of theirs. This seems to show that, even though Portuguese psychologists may have little awareness about the goals of their profession, at least they are aware of its fundamental technical dimensions, which hints that, at that level, training is adequate. Since psychological assessment is the most visible side of the objective application of psychological science (Gonçalves, Simões, \& Almeida, 2017; Ricou 2014), it is natural to consider that universities and researchers themselves might be concentrating on learning and on becoming an expert in technique, rather than learning the professional activity. Moreover, we must consider the answers provided by $7 \%$ of the participants referring to the administration of psychological assessment instruments, which again stresses this technical dimension of the profession.

Besides psychological assessment, $26 \%$ of participants indicate psychotherapy as an exclusive activity of psychologists. Such an answer is inevitably surprising, since psychotherapy has its origins in medicine, more specifically, in psychiatry (Jung, 1981). Moreover, other health professionals besides psychiatrists and psychologists are very often credited by the entities that offer this type of professional activity. For this reason, to define psychotherapy as a technique that is exclusive to psychology is, to say the least, a mistake. Indeed, it would be necessary to properly establish, as was already said in concern to counseling, the difference between $\mathrm{PI}$ and psychotherapy, or even, the difference between psychotherapy that is performed by psychologists and the one performed by other professionals. Even so, and somehow surprisingly, in some countries such as Germany, Brazil, or Luxembourg, psychotherapy is extended as the logical corollary of a clinical psychologist's training (e.g., CFP, 2000; SLP, 2015; Wegner, 2012).

Other activities that are mentioned, even if less frequently, are coaching, training, and teaching. In the case of coaching, the problem is similar to the one related to counseling and psychotherapy, seeing that there are many people who claim to practice coaching and who are not psychologists. In regard to training and teaching, the answers can be interpreted in light of the idea that participants were referring to training and teaching in the field of psychology. Regardless of the strength of the argument, it is always questionable that such activities are part of the psychological intervention.

It is important to stress that a total of seven psychologists claimed that there is no activity that can be considered as exclusive to psychologists.

If it is possible to consider to be true the premise stating that the only exclusive activity of psychologists is psychological assessment. About $30 \%$ of the collected sample of Portuguese psychologists failed to acknowledge this notion.

The third theme under study relates to the psychologists' perceptions concerning their activities that can be performed by other professionals. Here, $22 \%$ of psychologists participating in this survey refer that their tasks as psychologists cannot be performed by other professionals. Such an answer reveals a mistaken belief. It may suggest that the psychologists who 
answered this way feel insecure about their role and work as psychologists in the context of multidisciplinary teams, and for this reason they believe, or try to convince others, that their tasks cannot be performed by, or at least shared with, professionals working in different areas. To these $22 \%$, it is possible to add the other $11 \%$ answers that were placed in the "does not know/does not answer" subcategory, making up a total of $33 \%$ of the answers based on the lack of knowledge about the collaboration with other professionals.

Furthermore, it is important to put a particular emphasis on the answers referring to psychological assessment, as well as to vocational guidance and career development. Since it is common knowledge that these activities are exclusively performed by psychologists, it is cause of surprise and concern to see them identified by participants as activities that can be performed by professionals who are not psychologists.

To conclude, many of the collected answers appear to be associated to the specific practice of each individual. For instance, concerning the definition of the specific goal of $\mathrm{PI}, 83$ collected answers (41.5\%) are associated to clinical dimensions (to promote wellbeing, to promote change, to promote mental health, therapeutic act, psychotherapy, to promote emotional balance). When analyzing the characteristics of this sample, $43 \%$ of psychologists identify themselves as being associated to the clinical and health areas, which strengthens this conclusion. Thus, psychologists seem to define their professional identity according to their specialty area, ignoring psychology as a whole. The observed trend in such results is in tune with the assumptions defended by Ciampa (1986), who suggests that identity modes are determined by the historical and social context in which an individual is placed. Also Schein (1996) considers that it is through professional development that identity is affirmed, as a result of a person's knowledge and professional vocations.

\section{Conclusion}

Assuming that the performance of a profession demands a certain training or specialization, supported by a set of principles and beliefs with the purpose of attaining a certain goal (Ricou, 2014), and considering the results from the present study, it becomes necessary to delimit the exclusive goal of PI. Indeed, psychology has a clear set of professional principles (Ricou, Sá, \& Nunes, 2017), and, in order to become a psychologist, it is necessary to accomplish a set of well-defined conditions, in light of the EuroPsy definitions (EFPA, 2017). Nonetheless, the goal of psychology does not seem to be clear enough.

As acknowledged in this study, and despite its limitations concerning external validity, namely due to its sampling method, the promotion of well-being is a goal of $\mathrm{Pl}$, and yet, this goal is not exclusive to $\mathrm{PI}$, but rather shared with other interventions in the field of health.

The set of results provided by this study show the clear difficulty in defining the goal of PI as a whole, with such goals being primarily defined by each psychologist according to her/his specialty. This way, psychology as a profession might lose its identity more and more, diluting in its specialties, which - to aggravate the case - are starting to become autonomous and embody activities performed even by professionals who are not psychologists. An example is the practice of psychotherapy that, in some countries (e.g., Portugal), is a professional activity dissolved in models and professionals with a diversified training and identity (e.g., psychiatrists, social workers). Thereby, it seems to have become difficult to define the exclusive goal of $\mathrm{PI}$, one that is comprehensive enough to enclose all the intervention areas of psychologists. Consequently, it seems clear that psychologists would find it very hard to explain, to someone who is not a psychologist, what is it that truly defines $\mathrm{PI}$, and what sets it apart from all other forms of intervention that exist in different areas. As example, we may address the difference between a psychologist and a psychotherapist who is not a psychologist; between a psychologist and a counselor; between a school psychologist and an education coach; between a psychologist who works in an organization and a human resources manager. 
The same happens when we analyze the answers related to the exclusive tasks performed by psychologists, and the ones that may be performed by other professionals as well. The content analysis of the collected answers is unsettling, given the lack of knowledge shown by a few participants (e.g., "I do not know/l do not want to answer") in both questions. Surely that $70 \%$ of answers indicate that psychological assessment is an exclusive activity of psychologists, and yet, it is not wise to devalue that an alarming 30\% of psychologists do not know, or even affirm that there is no exclusive task performed by them as psychologists.

Psychologists seem to define their professional identity according to the field of activity in which they work. Such an observation is an indicator that psychologists identify first and foremost with their specialty, instead of identifying primarily with psychology, which can result in a devaluating process of psychology as a profession, resulting in a numerous set of activities with a lack of theoretical body. In a few years, we may have many psychotherapists (even with a theoretical body called "integrative psychother$\left.a p y^{\prime \prime}\right)$, many coaches in different fields, and so on, and few psychologists.

Bearing the aforementioned in mind, it is urgent to define clearly what is the exclusive and unique goal of PI, the one that gives it identity. If psychologists themselves cannot answer these questions, or if this professional class lacks agreement, other professionals and people in general surely will not be able to do so. In this sense, we ask ourselves: until what extent does this jeopardize the public's confidence in psychology? To answer this question, and considering the results from this study, it is relevant to deepen the knowledge about the identity of psychologists by analyzing the perceptions of other professionals with whom psychologists work with, as well as of the general public, a goal which we intend to pursue in future research. To do so, it is necessary to replicate this study at an European level, by assessing a representative sample of psychologists, in order to build a wider comprehension of psychologists' perceptions about $\mathrm{PI}$, and also, about the activities that they perform exclusively, or in common.

\section{References}

American Psychology Association (2017a). Understanding psychological testing and assessment. Retrieved from http://www.apa.org/helpcenter/assessment.aspx

American Psychology Association (2017b). Pursuing a career in counseling psychology. Retrieved from http://www.apa.org/action/science/counseling/education-training.aspx

Antunes, M. (1999). O processo de autonomização da psicologia no Brasil [The process of autonomisation of psychology in Brazil]. Psicologia \& Sociedade, 11(1), 1626.

Atkinson, R. L., Atkinson R. C., Smith E. E., Bem D. J., \& NolenHoeksema, S. (2002). Introdução à psicologia de Hilgard [Hilgard's introduction to psychology] (13th ed.). Porto Alegre: Artmed Editora.

Bardin, L. (2009). Análise de conteúdo [Content analysis]. Lisboa: Edições 70.

Ciampa, A. (1986). Identidade. In S. Lane \& W. Codo (Orgs.), Psicologia social: $O$ homem em movimento [Social psychology: Moving mankind] (pp. 58-75). São Paulo: Brasiliense.

Coutinho, M. (1999). Trabalho e construção da identidade [Work and development of identity]. Psicologia em Estudo, 4(1), 29-43.

Conselho Federal de Psicologia (2000). Resolução CFP no 10/00. Retrieved from http://site.cfp.org.br/resolucoes/resolucao-n-10-2000/

Chizzotti, A. (2003). A pesquisa qualitativa em ciências humanas e sociais: Evolução e desafios [Qualitative research in human and social sciences: Progression and challenges]. Revista Portuguesa de Educação, 16(2), 221-236.

European Commission (2016). Overview of the regulatory framework in the health services sector - Psychologists and related professions. Retrieved from ec.europa.eu/DocsRoom/documents/16683/attachments/1/.. .$/ p d f$

European Federation of Psychologists' Associations (2017). EuroPsy - The European certificate in psychology. Retrieved from http://www.europsyefpa.eu/sites/default/files/page/EuroPsy\%20Regulations\%20July\%202017\%20Amsterdam.pdf

Eysenk, M. (1998). Psychology: An integrated approach. New York: Addison Wesley Longman Limited.

Gauthier, J. (2005). Toward a universal declaration of ethical principles for psychologists: A progress report. In M. J. Stevens \& D. Wedding (Eds.), Psychology: IUPsyS Global Resource. Hove UK: Psychology Press.

Goodman, L. (1961). Snowball sampling. Annals of Mathematical Statistics, 32, 148-170.

Goodwin, J. (2015). A history of modern psychology (5th ed.). Hoboken: Wiley.

Gonçalves, M., Simões, R. M., \& Almeida, L. S. (2017). Psicologia clínica e da saúde: Instrumentos de avaliação. Lisboa: PACTOR.

Hammel, K., Carpenter, C., \& Dyck, I. (2000). Using qualitative research: A practical introduction for occupational and physical therapists. Edinburgh: Churchill Livingstone.

Hilgard, E. R. (1987). Psychology in America: A historical survey. San Diego: Harcourt Brace Jovanovich.

Jacques, M. (1996). Identidade e trabalho: Uma articulação indispensável. In A. Tamaio, J. Borges-Andrade, \& W 
Codo (Orgs.), Trabalho, organizações e cultura [Work, organizations, and culture] (pp. 41-47). São Paulo: Coletâneas da ANPEPP.

Jung, C. (1981). A prática da psicoterapia [The practice of psychotherapy]. Petrópolis: Editora Vozes.

Leal, I., Pimenta, F., \& Marques, M. (2012). Intervenção em psicologia clínica e da saúde. In I. Leal, F. Pimenta, \& M. Marques (Coords.), Intervenção em psicologia clínica e da saúde: Modelos e práticas [Intervention in clinical and health psychology: Models and practices] (pp. 11-16). Lisboa: Placebo Editora.

Mendras, H. (1975). Princípios da sociologia [Principles of sociology]. São Paulo: Zahar Editora.

Ordem dos Psicólogos Portugueses (2014). Os números da ordem: Resultados do censo dos membros efetivos [The numbers of the association: Results from a census to effective members]. Retrieved from https://www.ordemdospsicologos.pt/pt/noticia/1246

Ordem dos Psicólogos Portugueses (2016). Regulamento geral de especialidades profissionais da OPP [General regulation of professional specialties of OPP]. Retrieved from https://www.ordemdospsicologos.pt/pt/especialidades.

Pinto, A. C. (2001). Psicologia geral [General psychology]. Lisboa: Universidade Aberta.
Ribeiro, J. L. (1999). Investigação e avaliação em psicologia e saúde [Research and assessment in psychology and health]. Lisboa: CLIMEPSI Editores.

Ricou, M. (2014). A ética e a deontologia no exercício da psicologia [Ethics and deontology in the practice of psychology]. Lisboa: Ordem dos Psicólogos Portugueses.

Ricou, M., Sá, E., \& Nunes, R. (2017). The ethical principles of the Portuguese psychologists: A universal dimension. Journal of Medicine and Philosophy, 42(2), 199-213. doi: $10.1093 / \mathrm{jmp} / \mathrm{jhw} 066$

Société Luxembourgeoise de Psychologie (2015). La profession de psychothérapeute [The profession of the psychotherapist]. Retrieved from https://www.slp.lu/dossier-psychotherapie/

Schein, E. (1996). Identidade profissional: Como ajustar suas inclinações a suas opções de trabalho [Professional identity: How to adjust its inclinations to work options]. São Paulo: Nobel.

Teixeira, J. C. (2004). Psicologia da saúde [Psychology of health]. Análise Psicológica, 3(22), 441-448.

Trindade, I., \& Teixeira, J. C. (2002). Psicologia em serviços de saúde: Intervenção em centros de saúde e hospitais [Psychology in health services: Intervention in health centers and hospitals]. Análise Psicológica, 20(1), 171-174.

Wegner, P. (2012). A formação do psicanalista na Alemanha e Europa [The training of the psychoanalyst in Germany and Europe]. Jornal de Psicanálise, 45(82), 45-55. 